\title{
Association of serum hormone profile and semen quality of infertile males in and around Chennai
}

\author{
K. Palani ${ }^{1 *}$, A. Abdul Jabbar ${ }^{1}$, N. Jagannathan ${ }^{2}$, T. Babu Thangadurai ${ }^{3}$
}

\begin{abstract}
${ }^{1}$ Department of Chemistry, The New College (Autonomous), Chennai, Tamil Nadu, India
${ }^{2}$ Department of Biotechnology, School of Life Sciences, Vels University, Chennai, Tamil Nadu, India

${ }^{3}$ Department of Zoology, Arignar Anna College (Arts and Science), Krishnagiri, Tamil Nadu, India
\end{abstract}

Received: 14 October 2020

Revised: 23 October 2020

Accepted: 26 October 2020

\author{
*Correspondence: \\ K. Palani, \\ E-mail: palanik1213@gmail.com
}

Copyright: () the author(s), publisher and licensee Medip Academy. This is an open-access article distributed under the terms of the Creative Commons Attribution Non-Commercial License, which permits unrestricted non-commercial use, distribution, and reproduction in any medium, provided the original work is properly cited.

\section{ABSTRACT}

Background: The infertility rate in India has also increased gradually along with population growth. Based on the geographic, the prevalence of male infertility varies. It is noticed that around the world 60-80 million couples with infertility problem every year. The aim of the study was to assess the correlation between the serum hormones and semen quality in infertile males.

Methods: This research study was conducted in 60 infertile males aged from 20-50 years who reported at the Department of Andrology, Kanmani Fertility Centre (Pvt. Ltd.), Chennai, Tamil Nadu, India. The semen and hormone analysis was done in all study participants and its correlation was studied using SPSS (statistical product and service solutions) software.

Results: The results demonstrate that among the study participants, $15.0 \%$ of them were normozoospermia, asthenozoospermia (26.6\%), asthenoteratozoospermia (21.6\%), oligoasthenozoospermia (16.6\%) and oligoasthenoteratozoospermia (20.0) respectively. The results of Pearson correlation revealed that TSH, FSH, LH and PRL show a negative correlation but TST level shows a positive correlation with semen parameters.

Conclusions: This study concludes that the serum hormones concentration was observed abnormal in infertile males which show negative correlation with semen parameters of the study participants.

Keywords: Semen, Hormones, Infertility, Motility, Sperm count, Morphology

\section{INTRODUCTION}

Hormones play a very important function in initiating and maintaining the male reproductive system, it is not yet clear that how the variability in the concentration of sex hormones impact the quality of semen. Hormones can use as indicators to predict the semen quality. In earlier, thought that there is no relationship between the thyroid hormones and male infertility, but recently recognized that the level of thyroid hormones can influence the spermatogenesis. $^{1}$ Abnormal production of thyroid hormones during testis development at a younger age has been shown an effect on testis maturation at reproductive age. $^{2} \mathrm{FSH}$ and $\mathrm{LH}$ have a synergic effect on the growth and protection of testicular function in males. ${ }^{3} \mathrm{FSH}$ is one of the main hormones in the male reproductive system and helps in sertoli, granulosa cells function and production of male gametes. Initiation of sperm production at puberty stage and maintain the healthy sperm production in the male based on the concentration of FSH. ${ }^{4}$ Higher levels of prolactin directly affect sexual system through central nervous system and inhibit the production of androgen. Libido does not return to normal when the individual with high level of prolactin. ${ }^{5}$ The production of testosterone by leydig cells are initiated through LH, which plays an important role in sperm 
production. Abnormal production of LH directly affects the sperm production lead to male infertility. ${ }^{6} \mathrm{~A}$ wide range of proteins such as estrogen, activin, follistatin, and cytokines secreted locally have paracrine/autocrine regulation on sperm production. Similarly, other hormones like leptin, growth hormone $(\mathrm{GH})$, insulin-like growth factor-1 (IGF-1) and thyroid hormone are involved in sperm production. A hormonal concentration between the central nervous system and the testis control the sperm production. Imbalance in hormonal concentration has a negative impact on male infertility. ${ }^{7}$ Achievement of natural pregnancy rate was increased by hormonal treatment and also strengthens the sperm to fertilize the oocyte. Testicular steroid hormone and antisperm antibody (ASA) have a strong relationship which affects the motility of the ejaculated sperm. Abnormal sperm morphology such as damaged sperm, tail defects, head defects, neck defects and genital tract infection cause loss of motility. Antisperm antibody directly influences the in-vivo and in-vitro fertilization process and reduce the pregnancy rate by about $18 \%$. Sex chromosomal abnormalities and gonad failure are associated with hormonal imbalance and its variants. Chronic use of the drug like steroids, spironolactone, cimetidine, and ketoconazole inhibit gonadotropin secretion and lower testosterone level. Celiac disease also causes infertility in male show abnormal motility and count, which is associated with androgen resistance (high-serum testosterone and high-LH concentrations). Thus, main objective of the current study was also to examine the relationship between the serum hormones and semen quality of infertile male in and around Chennai, Tamil Nadu, India.

\section{METHODS}

\section{Study area}

A cross sectional study was conducted from December 2014 to November 2015 at the Department of Andrology, Kanmani Fertility Centre (Pvt. Ltd.), Chennai, Tamil Nadu, India. The constituted research ethical committee of The New College Institutional Ethical Committee was approved this research proposal and the informed consent was obtained from the individual participant.

\section{Study sample size}

A total no of 60 infertile men from in and around Chennai, Tamil Nadu, were participated in this study. Sample size was calculated using sample size determination in health studies formula and a prevalence of $10 \% .^{8}$

\section{Inclusion criteria}

Male subjects aged 20-50 years who had history of infertility for more than year and who sought help for infertility from the Kanmani fertility centre (Pvt. Ltd.), Chennai, Tamil Nadu, India, was recruited.

\section{Semen collection}

The below protocols are delineated and followed as recommended by WHO, (2010). ${ }^{9}$ The participants were advised to collect the semen sample in a separate room near to the analytical lab by masturbation and the ejaculate was collected into sterile wide mouth container. Lab technician use to get all information from the participants regarding the collection methods and loss of any fraction of the sample. The sample container was marked with participant name, study id, semen collection date time and ethics number.

\section{Sperm motility}

The motility of the sperm within the collected semen was examined immediately after liquefaction of the semen sample. The sample was mixed well without any air bubbles to avoid sedimentation of spermatozoa. The homogenous sample was used to prepare wet slides with $20 \mathrm{~mm}$ cover slip, which allow sperm swim freely. The slides were examined under microscopically at $20 \mathrm{X}$ and 40X magnifications to assess the different grades like progressive motility (PR), non-progressive motility (NP) and immotility (IM). The motility of sperm was calculated in percentage $(\%)$.

\section{Sperm concentration}

The hemocytometer was used to examine the concentration of sperm in the semen sample. $50 \mu \mathrm{l}$ of well mixed liquefied semen sample was mixed with 950 $\mu \mathrm{l}$ of the semen diluting fluid (diluting fluid: $10 \mathrm{ml}$ of $35 \%$ formalin mixed with $50 \mathrm{~g}$ of sodium bicarbonate after completely dissolve add $5 \mathrm{ml}$ of aqueous gentian violet and make up the final volume to $100 \mathrm{ml}$ ). A small drop $(10 \mu \mathrm{l})$ of diluted sample was applied in hemocytometer and covered with a cover slip. The concentration of sperm was counted after 5 minutes in the central square of the chamber using light microscope at $20 \mathrm{X}$ and $40 \mathrm{X}$. The concentration of sperm was calculated as million/ml of the semen sample.

\section{Sperm morphology}

The morphology of sperm which includes, defects of sperm head (amorphous, tapering, swollen, vacuolated, large, small and double head), mid-piece (absent of midpiece, thin and bend mid-piece) and tail (hairpin, broken, irregular, coiled, and multiple) were observed in wet preparation slide stained with papanicolaou method. The morphology of sperm was calculated in percentage (\%).

\section{Hormonal assay}

Hormonal screening can be limited to determining the levels of thyroid stimulating hormone (TSH), follicle stimulating hormone (FSH), luteinizing hormone (LH), prolactin (PRL) and testosterone (TST) in cases of abnormal semen parameters. All men were participating 
in a study to explore the role of environmental toxins and lifestyles on male infertility. Fasting venous blood samples were obtained from study population. Serum samples were separated by centrifugation at $3000 \mathrm{rpm}$ for $15 \mathrm{~min}$, and stored at $-20^{\circ} \mathrm{C}$ until the time of analysis. Serum levels of TSH, FSH, LH, PRL and TST were measured using beckmen coulter access 2 (electrochemiluminescence immunoassay (ECLIA).

\section{Statistical analysis}

The experiments conducted in triplicates in this study were subjected to various statistical analyses using SPSS software that the standard error mean and $p$ value significance were estimated and the results were inferred for logical interpretations.

\section{RESULTS}

Totally 100 participants who visited to Kanmani Fertility Center (Pvt. Ltd.), Chennai for fertility problem were asked the consent to participate, but only 60 participants willing to enroll the study. Based on semen parameters include sperm count, motility and morphology, the enrolled study participants were grouped into five categories (Table 1), namely normozoospermia (15.0\%), asthenozoospermia (26.6\%), asthenoteratozoospermia (21.6\%), oligoasthenozoospermia (16.6\%) and oligoasthenoteratozoospermia (20.0).

Group 1: normozoospermia- infertile participants have more than $15 \mathrm{million} / \mathrm{ml}$ of sperms in semen without any motility and morphological changes. Group 2: asthenozoospermia-infertile participants have higher level of immotile sperm compared with normal. Group 3: asthenoteratozoospermia- infertile participants have higher level of non-motile sperm and abnormal morphology compared with normal. Group 4: oligoasthenozoospermia- infertile participants have lower level of sperm count ( $<15$ million/ml) and reduced motility than normal level. Group 5: oligoasthenoteratozoospermia- infertile participants with lower level of sperm count, sperm motility and abnormal morphology compared with normal.

Table 1: Group wise distribution of participants based on semen parameters.

\begin{tabular}{|lll|}
\hline Group & Diagnosis & $\mathbf{N}(\%)$ \\
\hline $\mathbf{1}$ & Normozoospermia & $9(15.0)$ \\
\hline $\mathbf{2}$ & Asthenozoospermia & $16(26.6)$ \\
\hline $\mathbf{3}$ & Asthenoteratozoospermia & $13(21.6)$ \\
\hline $\mathbf{4}$ & Oligoasthenozoospermia & $10(16.6)$ \\
\hline $\mathbf{5}$ & Oligoasthenoteratozoospermia & $12(20.0)$ \\
\hline
\end{tabular}

\section{Semen parameters}

Table 2 shows the semen analysis of the study participants and results shows that the mean sperm count was $87.1 \mathrm{million} / \mathrm{ml}$ (group 1), $54.4 \mathrm{million} / \mathrm{ml}$ (group 2), $46.7 \mathrm{million} / \mathrm{ml}$ (group 3), $8.8 \mathrm{million} / \mathrm{ml}$ (group 4) and $6.3 \mathrm{million} / \mathrm{ml}$ (group 5) respectively. The lower sperm count was seen in group 5 and the highest count was seen in group 1. The sperm count was ranged from 39 to 160 million/ml (group 1), 21 to $97 \mathrm{million} / \mathrm{ml}$ (group 2), 26 to $99 \mathrm{million} / \mathrm{ml}$ (group 3), 5 to $12 \mathrm{million} / \mathrm{ml}$ (group 4) and 2 to $13 \mathrm{million} / \mathrm{ml}$ (group 5) respectively. The motility of sperm was analyzed in all study participants and the results shows that group 1 participants with $61.6 \%$, followed by group $2(41.2 \%)$, group $3(22.3 \%)$, group 4 $(24.5 \%)$ and group $5(6.6 \%)$ of motile sperms respectively. The percentage of normal sperm morphology was recorded in all study participants. It was found that only $9.3 \%, 1.9 \%, 4.5 \%$ and $1.8 \%$ of normal sperms was found in group 2 to 5. Normozoospermia group was found with maximum normal sperm (18.2\%) and oligotetrazoospermia group was found with minimum normal sperm $(1.8 \%)$.

Table 2: Semen parameters of the study participants by group.

\begin{tabular}{|c|c|c|c|c|c|c|}
\hline $\begin{array}{l}\text { Semen } \\
\text { analysis }\end{array}$ & $\begin{array}{l}\text { Group } 1 \\
(\mathbf{n}=9) \\
(\text { Mean } \pm \text { SEM })\end{array}$ & $\begin{array}{l}\text { Group } 2 \\
(n=16) \\
(\text { Mean } \pm \text { SEM })\end{array}$ & $\begin{array}{l}\text { Group } 3 \\
(\mathbf{n}=13) \\
(\text { Mean } \pm \text { SEM })\end{array}$ & $\begin{array}{l}\text { Group } 4 \\
(\mathrm{n}=\mathbf{1 0}) \\
(\text { Mean } \pm \text { SEM) }\end{array}$ & $\begin{array}{l}\text { Group } 5 \\
(\mathrm{n}=12) \\
(\text { Mean } \pm \text { SEM })\end{array}$ & $\begin{array}{l}\text { P } \\
\text { value* }\end{array}$ \\
\hline Count (million/ml) & $87.1 \pm 36.6$ & $54.4 \pm 26.7$ & $46.7 \pm 20.6$ & $8.8 \pm 2.5$ & $6.3 \pm 4.4$ & $<0.01$ \\
\hline Motility (\%) & $65.5 \pm 6.3$ & $41.2 \pm 21.7$ & $22.3 \pm 20.5$ & $24.5 \pm 13.0$ & $6.6 \pm 11.9$ & $<0.01$ \\
\hline Morphology (\%) & $18.2 \pm 4.8$ & $9.3 \pm 4.0$ & $1.9 \pm 0.7$ & $4.5 \pm 2.9$ & $1.8 \pm 0.7$ & $<0.01$ \\
\hline
\end{tabular}

$* \mathrm{p}<0.05$ value denotes significance between groups.

\section{Hormones}

$T S H$

Hormones play a major role in reproduction. Even it is trace in human body it plays a vital role in reproduction. The hormone profile of the participants was evaluated in blood serum. Table 3 shows the hormone profile of participants and results shows that the mean TSH was 2.5 $\mu \mathrm{IU} / \mathrm{ml}, 2.2 \mu \mathrm{IU} / \mathrm{ml}, 6.5 \mu \mathrm{IU} / \mathrm{ml}, 7.4 \mu \mathrm{IU} / \mathrm{ml}$ and 10.0 $\mu \mathrm{IU} / \mathrm{ml}$ in group $1-5$, respectively.

Pearson correlation was applied to study the association between the hormones and semen parameters of the study groups (Table 4) and the results shows that mean sperm count $(\mathrm{r}=-0.20, \mathrm{p}<0.05)$, sperm motility $(\mathrm{r}=-0.99$, $\mathrm{p}<0.05)$, and sperm morphology $(\mathrm{r}=-0.15, \mathrm{p}<0.05)$ shows a negative correlation with TSH level (Figure 1). It was clear from figure that TSH concentration was found elevated in group 3-5 compare to group 1 and 2. 
Table 3: Concentration of hormones in the blood serum of the study participants.

\begin{tabular}{|c|c|c|c|c|c|c|}
\hline Hormone & $\begin{array}{l}\text { Group } 1 \\
(\mathbf{n}=9) \\
(\text { Mean } \pm \text { SEM })\end{array}$ & $\begin{array}{l}\text { Group } 2 \\
(\mathrm{n}=16) \\
(\text { Mean } \pm \text { SEM })\end{array}$ & $\begin{array}{l}\text { Group } 3 \\
(\mathbf{n}=13) \\
(\text { Mean } \pm \text { SEM })\end{array}$ & $\begin{array}{l}\text { Group } 4 \\
(\mathrm{n}=10) \\
(\text { Mean } \pm \text { SEM })\end{array}$ & $\begin{array}{l}\text { Group } 5 \\
(n=12) \\
(\text { Mean } \pm \text { SEM })\end{array}$ & $\begin{array}{l}\mathbf{P} \\
\text { value* }\end{array}$ \\
\hline $\begin{array}{l}\text { TSH } \\
(\mu \mathrm{IU} / \mathrm{ml})\end{array}$ & $2.5 \pm 0.9$ & $2.2 \pm 0.9$ & $6.5 \pm 1.5$ & $7.4 \pm 0.8$ & $10.0 \pm 1.2$ & $<0.05$ \\
\hline $\begin{array}{l}\text { FSH } \\
(\mathrm{mIU} / \mathrm{ml})\end{array}$ & $5.1 \pm 2.3$ & $4.9 \pm 2.9$ & $12.1 \pm 3.9$ & $14.6 \pm 9.8$ & $16.8 \pm 1.4$ & $<0.05$ \\
\hline $\begin{array}{l}\mathbf{L H} \\
(\mathbf{m I U} / \mathrm{ml})\end{array}$ & $4.6 \pm 2.0$ & $4.5 \pm 1.5$ & $8.6 \pm 1.2$ & $10.0 \pm 2.8$ & $12.3 \pm 3.4$ & $<0.05$ \\
\hline $\begin{array}{l}\text { PRL } \\
(\mathrm{ng} / \mathrm{ml})\end{array}$ & $10.3 \pm 3.8$ & $12.2 \pm 5.9$ & $14.9 \pm 6.6$ & $20.4 \pm 9.6$ & $25.4 \pm 4.6$ & $<0.05$ \\
\hline $\begin{array}{l}\text { TST } \\
\text { (ng/dl) }\end{array}$ & $840.1 \pm 68.4$ & $629.9 \pm 41.5$ & $440.3 \pm 26.3$ & $412.5 \pm 22.0$ & $338.8 \pm 62.2$ & $<0.05$ \\
\hline
\end{tabular}

$* \mathrm{p}<0.05$ value denotes significance between groups.

Table 4: Association of semen parameters with hormones concentration of the study participants.

\begin{tabular}{|c|c|c|c|c|c|c|}
\hline \multirow[b]{2}{*}{ Variables } & \multicolumn{2}{|c|}{ Sperm count } & \multicolumn{2}{|c|}{ Sperm motility } & \multicolumn{2}{|c|}{ Sperm morphology } \\
\hline & $\begin{array}{l}\text { Pearson } \\
\text { correlation }\end{array}$ & $P$ value & $\begin{array}{l}\text { Pearson } \\
\text { correlation }\end{array}$ & $P$ value & $\begin{array}{l}\text { Pearson } \\
\text { correlation }\end{array}$ & $P$ value \\
\hline $\begin{array}{l}\text { TSH } \\
(\mu \mathrm{IU} / \mathrm{ml})\end{array}$ & -0.20 & $<0.05$ & -0.99 & $<0.05$ & -0.15 & $<0.05$ \\
\hline $\begin{array}{l}\text { FSH } \\
(\mathrm{mIU} / \mathrm{ml})\end{array}$ & -0.32 & $<0.05$ & -0.12 & $<0.05$ & -0.11 & $<0.05$ \\
\hline $\begin{array}{l}\mathbf{L H} \\
(\mathrm{mIU} / \mathrm{ml})\end{array}$ & -0.26 & $<0.05$ & -0.15 & $<0.05$ & -0.11 & 0.38 \\
\hline $\begin{array}{l}\text { PRL } \\
(\mathrm{ng} / \mathrm{ml})\end{array}$ & -0.16 & $<0.05$ & -0.09 & $<0.05$ & -0.12 & $<0.05$ \\
\hline $\begin{array}{l}\text { TST } \\
\text { (ng/dl) }\end{array}$ & 0.47 & $<0.05$ & 0.35 & $<0.05$ & 0.25 & $<0.05$ \\
\hline
\end{tabular}
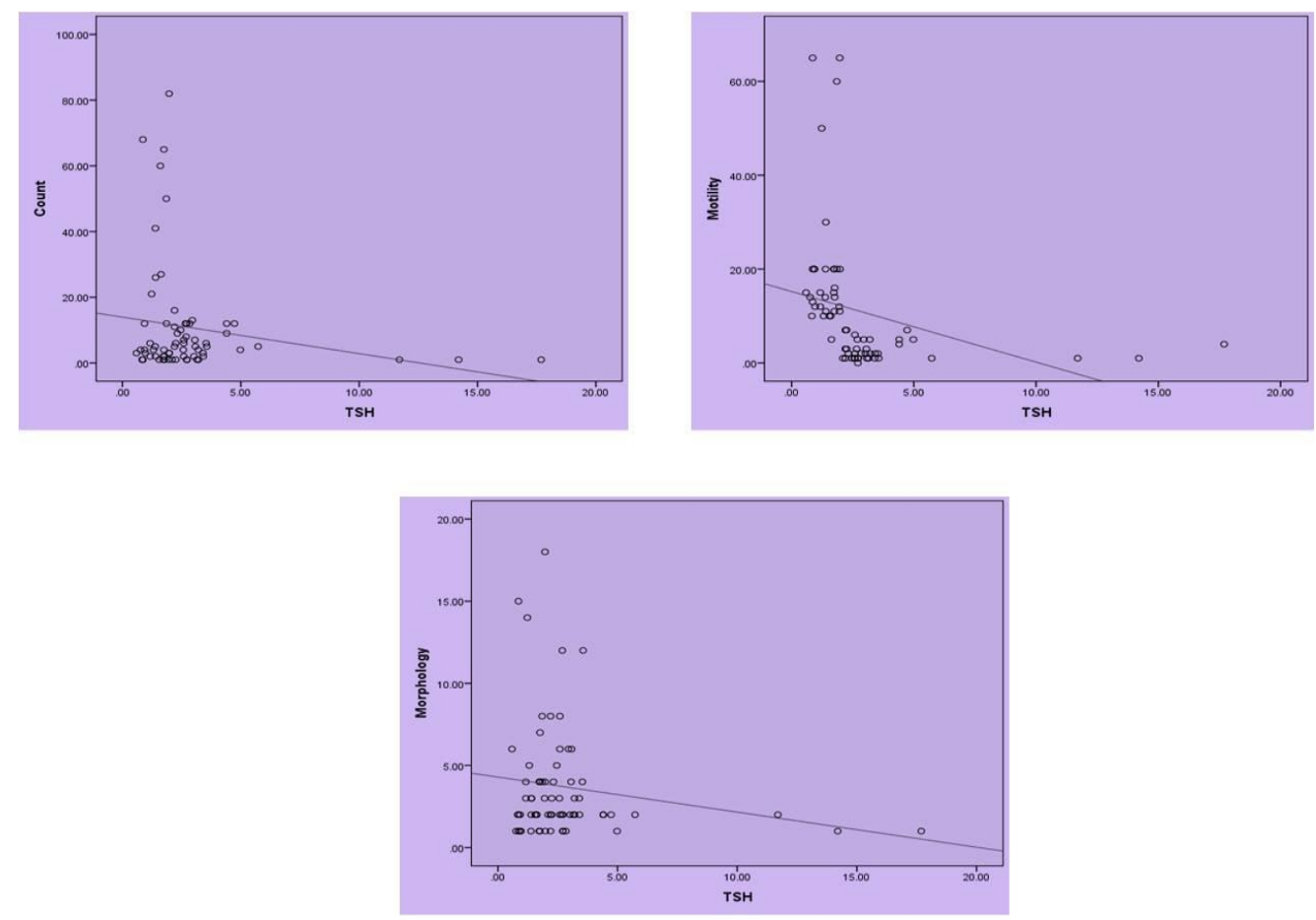

Figure 1: Scatter plots and linear regression lines of TSH level and semen parameters of the study participants. 

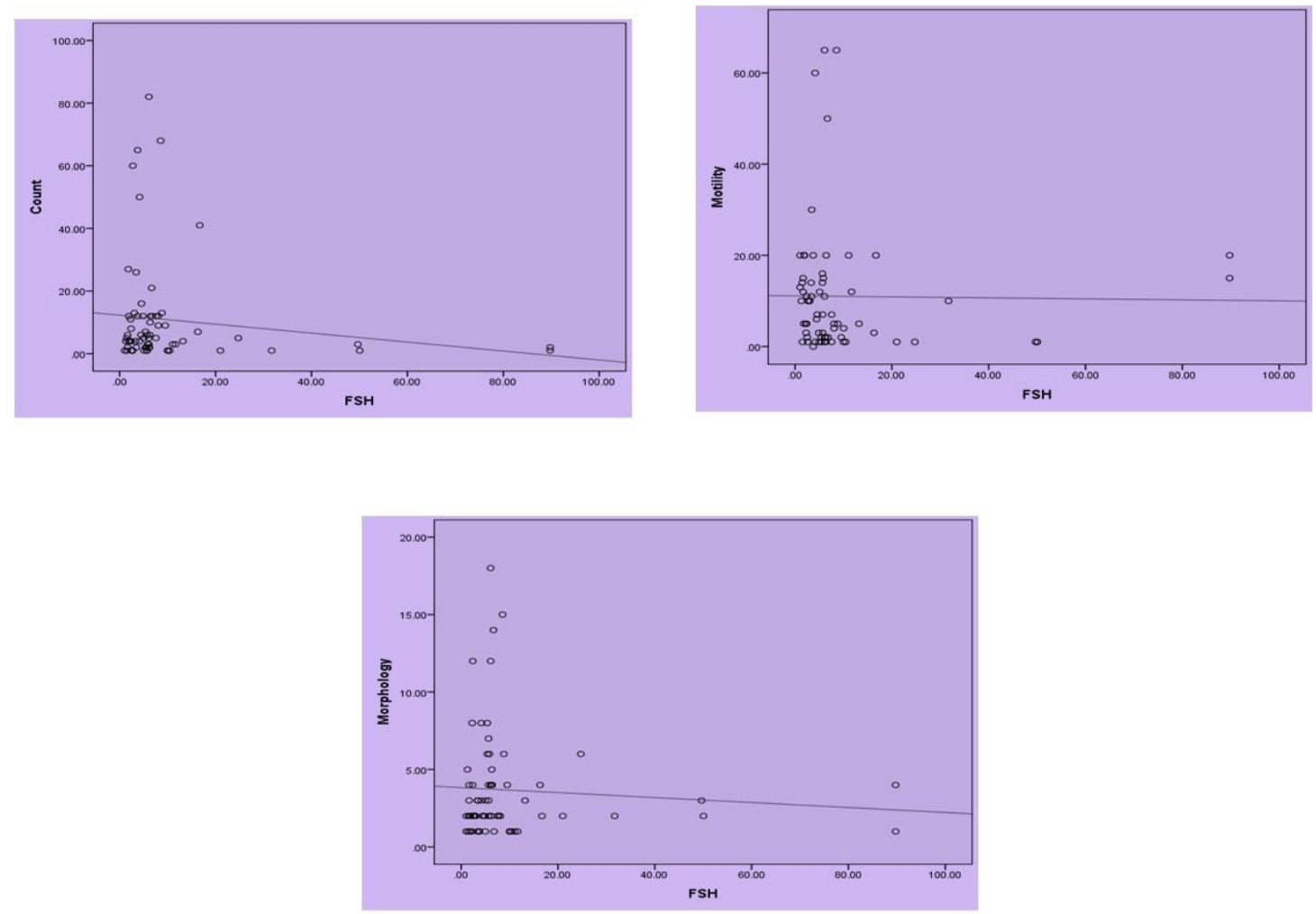

Figure 2: Scatter plots and linear regression lines of FSH level and semen parameters of the study participants.
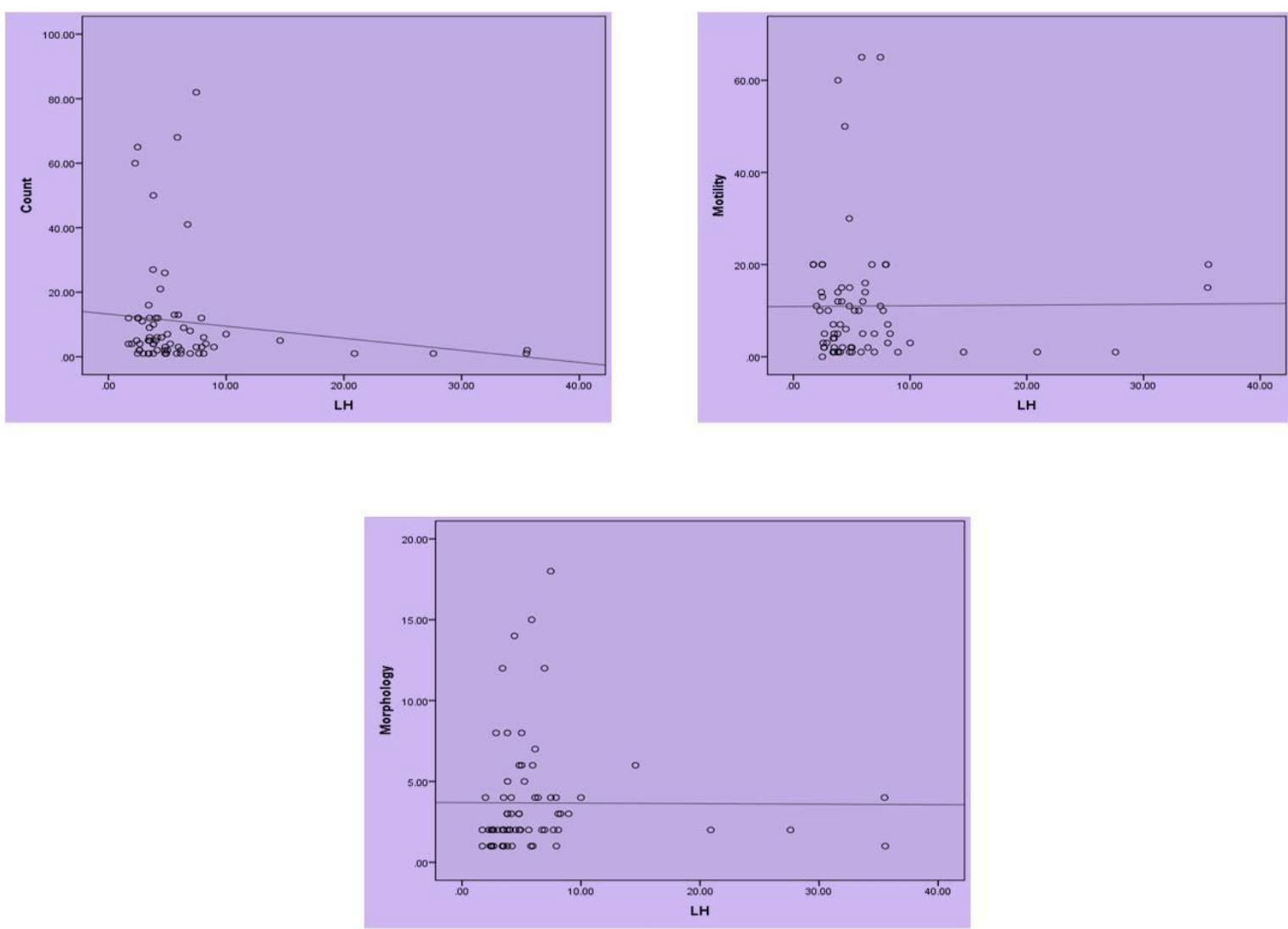

Figure 3: Scatter plots and linear regression lines of LH level and semen parameters of the study participants. 

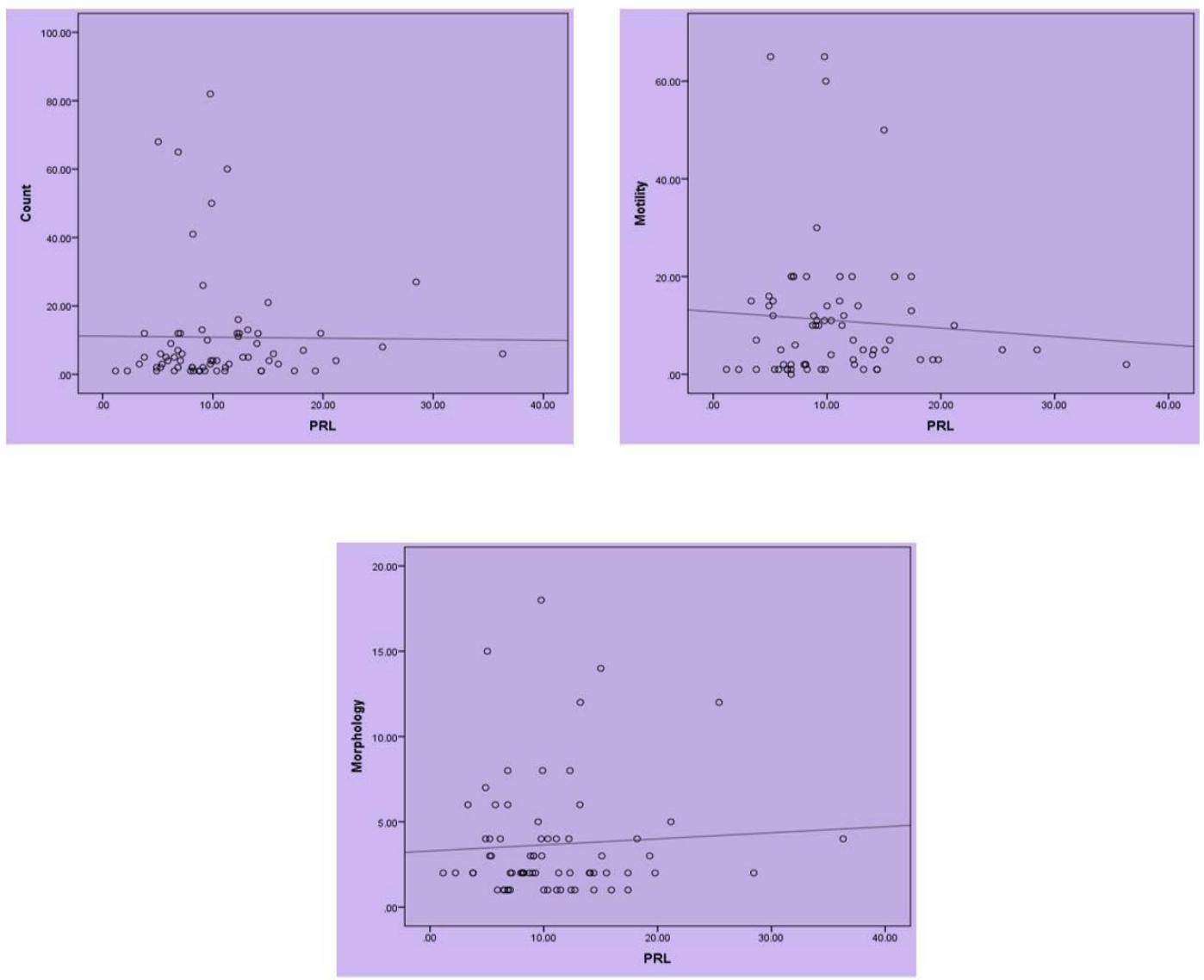

Figure 4: Scatter plots and linear regression lines of PRL level and semen parameters of the study participants.
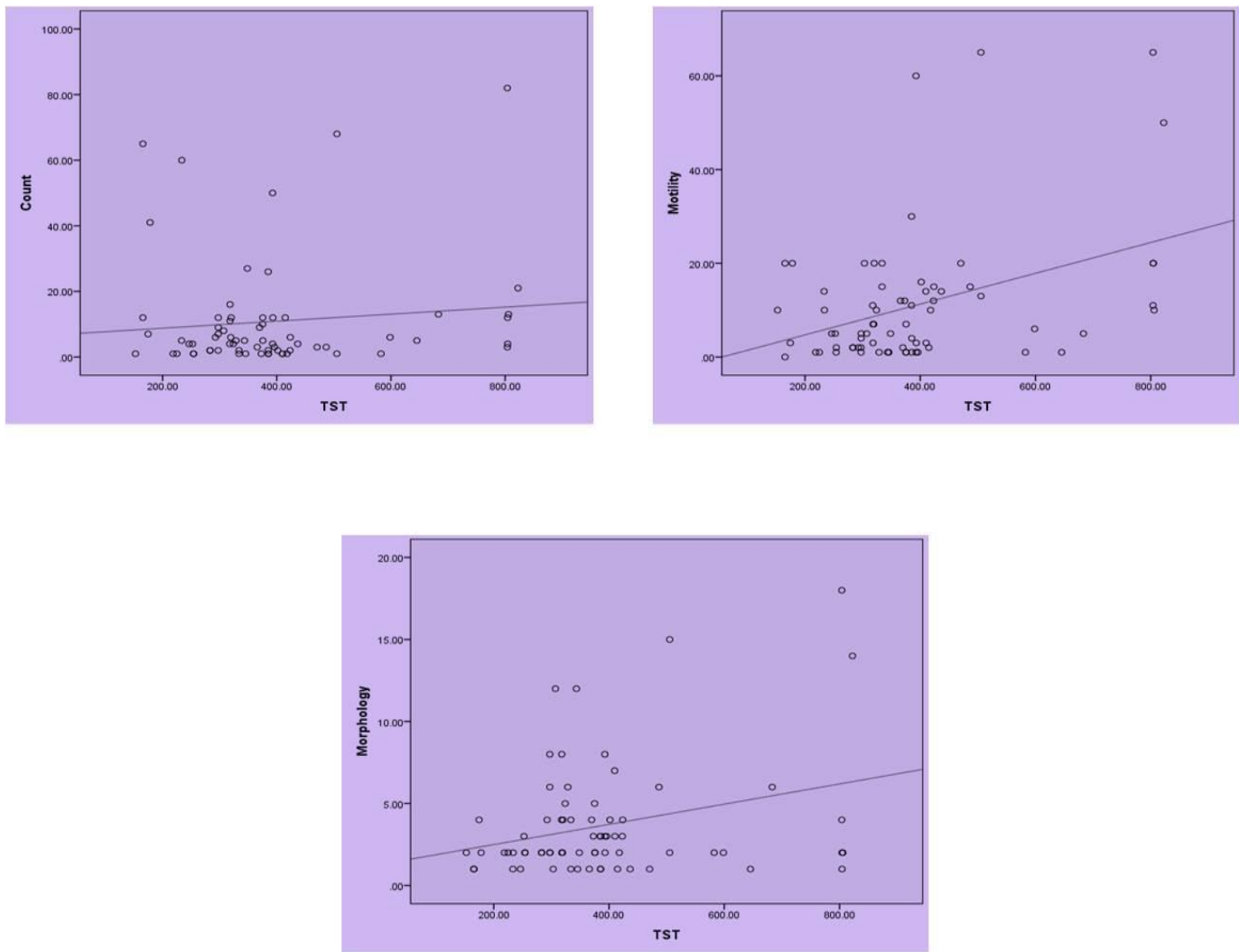

Figure 5: Scatter plots and linear regression lines of TST level and semen parameters of the study participants. 


\section{FSH}

FSH plays an important role in induction and maintenance of spermatogenesis in male, the abnormal concentration of FSH leads to male infertility. The mean FSH was $5.1 \mathrm{mIU} / \mathrm{ml}$ (group 1), $4.9 \mathrm{mIU} / \mathrm{ml}$ (group 2), $12.1 \mathrm{mIU} / \mathrm{ml}$ (group 3), $14.6 \mathrm{mIU} / \mathrm{ml}$ (group 4) and 16.8 $\mathrm{mIU} / \mathrm{ml}$ (group 5) respectively. The mean FSH was found significantly higher in group 2-5 compared to group 1 . Scatter plots shows that mean sperm count $(\mathrm{r}=-0.32$, $\mathrm{p}<0.05)$, sperm motility $(\mathrm{r}=-0.12, \mathrm{p}<0.05)$, and sperm morphology $(\mathrm{r}=-0.11, \quad \mathrm{p}<0.05)$ shows a negative correlation with FSH level (Figure 2).

\section{$L H$}

The production of testosterone by leydig cells are initiated through $\mathrm{LH}$, which plays an important role in sperm production. The mean $\mathrm{LH}$ level was $4.6 \mathrm{mIU} / \mathrm{ml}$, $4.5 \mathrm{mIU} / \mathrm{ml}, 8.6 \mathrm{mIU} / \mathrm{ml}, 10.0 \mathrm{mIU} / \mathrm{ml}$ and $12.3 \mathrm{IU} / \mathrm{ml}$ in groups $1-5$, respectively. Figure 3 shows that the mean sperm count $(\mathrm{r}=-0.26, \mathrm{p}<0.05)$, sperm motility $(\mathrm{r}=-0.15$, $\mathrm{p}<0.05)$ and sperm morphology $(\mathrm{r}=-0.11, \mathrm{p}>0.05)$, shows a negative correlation with $\mathrm{LH}$ level.

\section{PRL}

Exact role of prolactin in male reproduction health remains unclear. The mean PRL was $10.3 \mathrm{ng} / \mathrm{ml}$ in group $1,12.2 \mathrm{ng} / \mathrm{ml}$ in group 2, $14.9 \mathrm{ng} / \mathrm{ml}$ in group 3, 20.4 $\mathrm{ng} / \mathrm{ml}$ in group 4 and $25.4 \mathrm{ng} / \mathrm{ml}$ in group 5. Data from the scatter plots shows that the mean sperm count $(r=-$ $0.16, \mathrm{p}<0.05)$, sperm motility $(\mathrm{r}=-0.09, \mathrm{p}<0.05)$ and sperm morphology $(\mathrm{r}=-0.12, \mathrm{p}>0.05)$, shows a negative correlation with PRL level (Figure 4).

\section{TST}

TST is an important male hormone play a vital role in reproductive health. Abnormal levels may affect the sex drive and semen quality. The mean TST level was 840.1 $\mathrm{ng} / \mathrm{dl}$ in gruop $1,629.9 \mathrm{ng} / \mathrm{dl}$ in group $2,440.3 \mathrm{ng} / \mathrm{dl}$ in group 3, $412.5 \mathrm{ng} / \mathrm{dl}$ in group 4 and $338.8 \mathrm{ng} / \mathrm{dl}$ in group 5 respectively. It was shows that TST level was higher in group 2-5, when compared with group 1. Pearson correlation was applied to examine the correlation between TST level and semen parameters, the results shows that the mean sperm count $(r=0.47, p<0.05)$, sperm motility $(r=0.35, \mathrm{p}<0.05)$ and sperm morphology $(r=-$ $0.25, \mathrm{p}>0.05)$, shows a positive correlation with TST level (Figure 5).

\section{DISCUSSION}

The present investigation showed that the sperm count was observed lower than the normal range in abnormal group 2-5 compared to normal group 1. The sperm count plays an important role in pregnancy and many factors include pollution and environmental factors are responsible for low sperm count. Peter et al states that the success rate of IVF directly associated with sperm count. ${ }^{10}$ The study shows that around $2 \%$ of normozoospermia participants and $9 \%$ of oligozoospermia participants had sperm counts less than 10 million/ml which support our results. ${ }^{11} \mathrm{~A}$ study shows that the sperm count was increased above $100 \mathrm{million} / \mathrm{ml}$ by treating the dexamethasone for 9 months. 12 In our study mean age of group 2-5 participants were above 35 years and a study shows that the sperm counts were increased up to 34 years age and showing a decline phase immediately after 35 years. ${ }^{13}$

An internal and external changes in the body disturb the metabolism involved in head, neck and tail synthesis of sperm thus alter the motility. Rodney et al states that body temperature influences the sperm motility and concluded that the motility of sperm was gradually decreased if the temperature was increased. ${ }^{14}$ Boyle et al conclude that reduction in sperm motility was the major reason for male infertility and found that sperm velocity in the vagina strongly associated with the conceive ability. ${ }^{15}$ Study shows that in vivo and in vitro fertility capacity of sperm was assessed mainly by sperm motility. ${ }^{16}$ The types of sperm motility include the rapid, moderate and sluggish is a significant marker to assess the fertilizing capacity. Gustavo et al states that sperm motility should be assessed after washing procedure, he concludes that participant was asthenozoospermia before washing, but its motility is improved after washing the semen. After removal of seminal plasma on the asthenospermia is reduced from $37.4 \%$ to $23.1 \%$ and also found a reduction in sperm motility by addition of semen plasma in the washed sperm culture. ${ }^{17}$

Roy et al concludes that cell morphology examination is the best tool to diagnosis azoospermia. ${ }^{18}$ Low percentage of morphologically normal sperm cells was observed in group 2 to 5 subjects when compared to group 1, which is highly correlated with the fertilizing capacity of the subjects. Similar supportive results were also found by Roger et al. ${ }^{19}$ Gopalakrishnan et al also reported that minimum $14 \%$ of normal morphology sperms required achieving fertilization. In our study group 2 to 5 have less than $14 \%$ of normal morphology sperm cells. ${ }^{20}$

TSH level was observed high in group 2-5, when compared to group 1, similar finding was observed by Singh et al. ${ }^{21}$ Hyper or hypothyroidism is not very common in male, only $0.1 \%$ of the male in general population might have a thyroid problem. ${ }^{22}$ Study examines the relationship between spermatogenesis and hyperthyroidism in 21 patients and found that $43 \%$ of patients with low sperm counts and $61.9 \%$ of patients were with poor motility rate. ${ }^{23}$ Similar to our results found by Dipti Sarma et al observed negative correlation of TSH level with sperm count $(r=-0.73, p<0.05) .{ }^{24}$

Elevated levels of FSH lead to a reduction in testosterone level results in testicular failure and lower level lead to hypogonadotropic hypogonadism $(\mathrm{HH})$ and showed 
improvement in semen parameters after enhancing the FSH level. ${ }^{25}$ Madhusoodanan et al conducted in men who underwent microscopic subinguinal varicocelectomy and results show a significant correlation between sperm counts and pre-operative FSH $(\mathrm{r}=-0.31, \mathrm{p}<0.05){ }^{26}$ Supportive study was done by Mamiafo Corinne et al found a negative correlation between FSH and semen parameters in male partners of infertile couples. ${ }^{27} \mathrm{~A}$ study conducted in 161 oligozoospermic men found normal level of LH and TST, but FSH levels show a negative association with sperm count which supports our findings. ${ }^{28}$

Biswas et al found several fold higher concentrations of LH in seminal plasma when compare to serum and also found the concentration was lower in azoospermia compared to oligozoospermia and normozoospermia group. ${ }^{29}$ Eman et al states that the higher BMI is one of the risk factors for abnormal semen parameters. ${ }^{30}$ In this study found that obese oligozoospermia group shows abnormal LH level compared to normal group. This study shows a negative correlation of $\mathrm{LH}$ with sperm count $(\mathrm{r}=-0.41, \quad \mathrm{p}<0.05)$, motility $(\mathrm{r}=-043, \quad \mathrm{p}<0.05)$ and morphology $(\mathrm{r}=-0.04, \mathrm{p}<0.05)$, which supports our findings. Similar to our results the Bennet et al observed high LH level in oligozoospermia when compared to normozoospermia group. ${ }^{31}$ This shows that higher LH concentration leads to male infertility. Hueiwang Anna Jeng et al reported there is no significant difference in $\mathrm{LH}$ level among the smoker and non-smokers and also not found any association with semen parameters. ${ }^{32}$

A study with 212 males and divide them in hyperprolactinemia and normal prolactin group. ${ }^{33}$ Results show that there was significant negative correlation between prolactin and semen parameters, which support our findings. A study was conducted in 1465 patients to find the association between hyperprolactinemia and semen parameters. ${ }^{34}$ Results show that 85 patients detected with hyperprolactinemia with abnormal semen parameters but the association was very weak. AlDaghistani et al conducted study in 120 patients to study the association between PRL and semen parameters. ${ }^{35}$ Patients were grouped into asthenozoospermia, oligozoospermia, severe oligozoospermia, and azoospermia. Results show that the PRL level was found abnormal concentration in all study groups and shows a negative impact on semen parameters, which support our results. A comparative cross-sectional study conducted in 355 males of infertile couples shows that $86.0 \%$ of males having abnormal prolactin level also found with abnormal semen parameters $(\mathrm{p}=0.004$; or 3.50 , CI-1.43$8.55) .^{36}$

TST hormone is not only involved in sperm production; it was simulated by other sex hormones. The level of TST may be higher in seminal plasma compared to serum. Study conducted by Ramesh Babu et al observed significantly higher level of LH and FSH in infertile compare with fertile group, but there was no significant differences in TST level between the study groups. ${ }^{37}$ In contrast, study conducted by Ismael et al found a higher level of TST in fertile men compare to infertile men also found significant differences in sperm count, motility and morphology. ${ }^{38}$ Animal studies conducted shows reduction in TST and LH level, count and motility after food restriction. ${ }^{39}$ The mean TST level in the abnormal group was not within allowed range, Khan et al observed significant reduction of TST level in azoospermic and oligozoospermic compare to control group which supports our results. ${ }^{40}$

\section{CONCLUSION}

This study concludes that there could be multiple factors that bring changes in semen quality in the abnormal group 2 to 5 participants compared to normal group 1. It was noticed that most of the semen parameters was not within the range in group 2-5 compared to group 1 participants. This study concludes that the hormone profiles play an important role in male infertility. It was observed that abnormal hormone levels in group 2-5, which are significantly shows negative correlation with semen parameters when compared to the normal group. Pearson correlation shows that except testosterone and other hormones show a negative correlation with sperm count, motility and morphology.

Funding: No funding sources

Conflict of interest: None declared

Ethical approval: The study was approved by the Institutional Ethics Committee

\section{REFERENCES}

1. Singh R, Marie GM, Lee W, Ashok A. Thyroid, spermatogenesis, and male infertility. Front Biosci. 2011;E3:843-55.

2. Jannini EA, Ulisse S, Armiento M. Thyroid hormone and male gonadal function. Endoc Review. 1995; 16:443-59.

3. Matsumoto AM, Karpas AE, Paulsen CA, Bremner WJ. Reinitiation of sperm production in gonadotropin-suppressed normal men by administration of follicle-stimulating hormone. J Clin Invest. 1983;72(3):1005-15.

4. Tapanainen JS, Aittomaki K, Min J, Vaskivuo T, Huhtaniemi IT. Men homozygous for an inactivating mutation of the follicle-stimulating hormone (FSH) receptor gene present variable suppression of spermatogenesis and fertility. Nat Genet. 1997; 15:205-6.

5. Veldhuis JD, Iranmanesh A, Urban RJ. Primary gonadal failure in men selectively amplies the mass of follicle stimulating hormone (FSH) secreted per burst and increases the disorderliness of FSH release patterns: reversibility with testosterone replacement. Int J Androl. 1997;20:297-305.

6. Ramanujam LN, Liao WX, Roy AC. Association of molecular variants of luteinizing hormone with 
menstrual disorders. Clin Endocrinol. 1999;51:243246.

7. Sieber A. Endocrine fertility disorders in the male. Ther Umsch. 1992;49:181-5.

8. Lwanga SK, Lemeshow S. Sample size determination in health studies, A practical manual. World Health Organization 1991;1-3.

9. World Health Organization Department of Reproductive Health and Research. WHO laboratory manual for the examination and processing of human semen, Fifth Edition. WHO 2010.

10. Peter N, Sarah K. In Vitro Fertilization for Male Factor Infertility. J Clinic Endocrinol Metabol. 1997;82(3):709-16.

11. MacLecd J, Gold RZ. The male factor in fertility. II. Spermatozoon counts in 1000 men of known fertility and in 1000 cases of infertile marriage. J Ural. 1951;66:436-49.

12. Nicopoullos JDM, Ramsay JWA, Cassar J. From zero to one hundred million in six months: The treatment of azoospermia in congenital adrenal hyperplasia. Archiv Androl. 2003;49(4):257-63.

13. Stone BA, Alex A, Werlin LB, and Marrs RP. Age thresholds for changes in semen parameters in men. Fertil Steril. 2013;100(4):952-8.

14. Rodney A, Appell, MD, Paul R Evans. The effect of temperature on sperm motility and viability. Fertilit Steril. 1977;28(12):1329-32.

15. Boyle CA, Khoury MJ, Katz DF, Annest JL, Kresnow MJ, DeStefano F, Schrader S. The relation of computer-based measures of sperm morphology and motility to male infertility. Epidemiology. 1992;3:239-46.

16. Auger J, Kunstman J, Czyglik F, Jouannet P. Decline in semen quality among fertile men in Paris during the past 20 years. N Eng J Medic. 1995;332:281-5.

17. Gustavo FG, and Martha Z. Sperm Motility Should be Assessed in Fresh Sperm and After a Sperm Washing Procedure. Archiv Androl. 1992;28(2):839.

18. Roy S, Banerjee A, Pandey HC, Singh G, Kumari GL. Application of seminal germ cell morphology and semen biochemistry in the diagnosis and management of azoospermic subjects. Asia J Androl. 2001;3(2):55-62.

19. Rogers BJ, Bentwood BJ, Van Campen H. Sperm morphology assessment as an indicator of human fertilizing capacity. J Androl. 1983;4:119-25.

20. Gopalakrishnan, Hinduja IN, Anandkuumar TC. Assessment of mitochondrial activity of human spermatozoa. Mol Androl. 1990;3:243-53.

21. Singh Rajender, Marie Gray Monica, Lee Walter, Ashok Agarwal. Thyroid, spermatogenesis, and male infertility. Front Biosci. 2011;E3(1):843-55.

22. Krassas GE, Perros P. Thyroid disease and male reproductive function. $\mathbf{J}$ Endocrinol Invest. 2003;26:372-80.

23. Abalovich M, Levalle O, Hermes R, Scaglia H, Aranda C, Zylbersztein C. Hypothalamic-pituitary- testicular axis and seminal parameters in hyperthyroid males. Thyr. 1999;9(9):857-63.

24. Dipti Sarma, Uma Kaimal, Saikiaand Darvin, Vamadevan Das. Alteration of Sex Hormone and Semen Parameters in Adult Males with Subclinical Hypothyroidism. J Advanc Medic Medic Resea. 2017;23(3):1-7.

25. Rastrelli G, Corona G, Mannucci E, Maggi M. Factors affecting spermatogenesis upon gonadotropin-replacement therapy: a meta-analytic study. Andrology. 2014;2(6):794-808

26. Madhusoodanan V, Patel P, Blachman-Braun R, Ramasamy R. Semen parameter improvements after microsurgical subinguinal varicocele repair are durable for more than 12 months. Can Urol Assoc J. 2020;14(3):E80-3.

27. Corinne TM, Anatole PC, Jeanne NY. Comparison of Serum Inhibin $\mathrm{B}$ and Follicle-Stimulating Hormone (FSH) Level between Normal and Infertile Men in Yaoundé. Int J Reproduct Medic. 2020;2020.

28. Subhan F, Tahir F, Ahmad, R, Khan ZD. Oligospermia and its relation with hormonal profile. Pak Med Assoc. 1995;45(9):246-7.

29. Biswas S, Ferguson KM, Stedronska J. Fructose and hormone levels in semen: their correlations with sperm counts and motility. Fertil Steril. 1978;30:2004.

30. Eman M Abd Elhafeez, Amal A. Halawa, Mohamed F. Hamed, and Mamdouh M. Abouelmaged. Effects of Cadmium and /or Chromium on reproductive organs and semen profiles of male albino rats. Mans Veterina Medic J. 2019;20(3):14-8.

31. Bennet A, Bujan L, Plantavid M. Luteinizing hormone pulse frequency and in vitro bioactivity in male idiopathic infertility. Fertil Steril. 1991;55:6128.

32. Jeng Hueiwang, Chen Yi-Ling, Kantaria Khyati. Association of cigarette smoking with reproductive hormone levels and semen quality in healthy adult men in Taiwan. J Environment Sci Heal. 2014;49:262-8.

33. Ahmed Nada, Humeda Ahmed. The relationships between serum prolactin level and semen analysis parameters among patients attended the reproductive health center, Khartoum 2016-2017. Sudan Medic Monit. 2017;12:41-4.

34. Alıcı B, Citci A, Ozkara H, Akkuş E, Hattat H. The effect of the hyperprolactinemia on semen parameters in male infertility. Cerrahpaşa $\mathrm{J}$ Med 1998;29(2):95-8.

35. Al-Daghistani, Hala I. Evaluation of serum testosterone, progesterone, seminal antisperm antibody, and fructose levels among Jordanian males with a history of infertility. Biochem Res Int. 2010;1:1-8.

36. Omo-Aghoja LO, Ngwu M, Adeyinka AT. Hormonal parameters and semen microbiological pattern of infertile males: a comparative crosssectional study in Benin City, South South Nigeria. J West Afr Coll Surg. 2017;7(3):73-93. 
37. Ramesh Babu S, Sadhnani MD, Swarna M, Padmavathi P, Reddy PP. Evaluation of FSH, LH and Testosterone Levels in Different Subgroups of Infertile Males. Ind J Clinic Biochem. 2004;19:45-9.

38. Ismael ZK, AL-Anbari LA, Mossa HA. Relationship of FSH, LH, DHEA and testosterone levels in serum with sperm function parameters in infertile men. $\mathbf{J}$ Pharmaceut Sci Resear. 2017;9(11):2056-61.

39. Rehm S, White TE, Zahalka, EA, Stanislaus DJ, Boyce RJ, Wier PJ. Effects of food restriction on testis and accessory sex glands in maturing rats. Toxicol Pathol. 2008;36:687-94.
40. Khan MS, Zaman S, Sajjad M, Shoaib M, Gilani G. Assessment of the level of trace element zinc in seminal plasma of males and evaluation of its role in male infertility. Int $\mathbf{J}$ Appl Basic Med Res. 2011;1(2):93-6.

Cite this article as: Palani $\mathrm{K}$, Jabbar AA, Jagannathan N, Thangadurai TB. Association of serum hormone profile and semen quality of infertile males in and around Chennai. Int $\mathrm{J}$ Reprod Contracept Obstet Gynecol 2020;9:4860-9. 